\title{
Chapter 6 Behaviour of Containment Buildings
}

\subsection{Introduction}

The characteristics of the containment buildings of French PWRs are described in Section 2.3.2.3. Essentially, the containment building, sometimes called the third containment barrier for French reactors, must provide confinement of radioactive substances in the event of failure of the fuel rod cladding (first barrier) and reactor coolant system (second barrier). The best possible leak tightness for the containment building must therefore be sought from design and throughout the service life of the facility.

The containment building is the final barrier implemented to protect the public from radioactive substances released during an accident inside the containment. It includes:

- the reactor building itself (described in Section 2.3.2.3);

- penetrations into this building, which constitute containment discontinuities (i.e. the equipment hatch, personnel airlock, fluid penetrations, electrical penetrations and fuel assembly transfer tube);

- certain pipes, which constitute containment extensions, especially parts of the secondary systems inside the reactor building (in particular the main feedwater pipes and main steam pipes, and the secondary shell and tube bundles of the steam generators, where the tube bundles are also part of the second barrier).

Penetrations are designed to maintain adequate leak tightness under design-basis accident conditions. To achieve this, penetrations that carry fluids are fitted with check valves and isolation valves, most of which are automatically closed by the protection system. 
Furthermore, certain systems are considered extensions of the third barrier outside the containment building itself. These are sections of pipes and associated equipment that simultaneously meet the following criteria:

- they are outside the reactor building;

- they may carry either reactor coolant, following an accident that could lead to deterioration of fuel rod cladding (failure of the first barrier), or the containment atmosphere, to the outside of the containment following an accident that could lead to both deterioration of the first barrier and a release of activity from the reactor coolant into the containment (failure of the second barrier).

For example, for reactors in the current French fleet (excluding the EPR), systems could remain open to the outside of the containment or be brought into service by automatic opening of the containment isolation valves during an accident, for recirculation of water from the safety injection system (SIS) and the containment spray system (CSS), or via application of operating documents or guides (in particular, the Severe Accident Operating Guide).

On systems that constitute extensions of the third containment barrier, a failure (such as a line break) could lead to transfer of radioactive substances into buildings around the reactor building or into the environment (i.e. to bypass of the third containment barrier).

In situations where the first and second barriers have deteriorated, the integrity and leak tightness of the third containment barrier are essential for preventing the spread of radioactive substances into the environment. This is particularly true during loss of coolant accidents (LOCA), during which radioactive substances are released into the reactor coolant system (RCS) and the containment building. Their spread into the external environment therefore depends on the containment leakage rate and on any containment bypass, which could lead to direct releases of radioactivity into the environment. The quantity of radioactivity that escapes therefore depends on multiple phenomena: overpressure in the containment caused by the accident itself, the reactor building leakage rate at this pressure, and the quantity of radioactive substances present in the containment as gases or aerosols.

In the event of a core melt accident on reactors in the current fleet, the increase in pressure inside the containment would exert large loads onto it (which could be greater than those under the operating conditions used for design of the facility), eventually leading to deterioration of its walls. Increases in temperature and pressure inside the containment could lead to loads such that the maximum leakage rate of the containment adopted in design would be exceeded. This increase in the leakage rate could result from deterioration of the containment walls (in particular, permeability or cracking of the concrete walls could increase under the effect of the thermal and mechanical loads applied throughout facility operations and during the accident) or from changes in leakage around discontinuities in the containment building (penetrations, airlocks etc.).

In this chapter, Section 6.2 describes the behaviour of containment buildings under design-basis conditions for reactors in the current French fleet and the EPR. In particular, 
it covers leakage via the containment walls and the various penetrations for design-basis operating conditions.

Section 6.3 describes the behaviour of containment buildings under core melt accident conditions for reactors in the current fleet (900 MWe and 1300 MWe reactors).

Section 6.4 describes situations where there could be bypass of the third containment barrier (or its extension) on the current fleet, corresponding to reactor coolant, or the containment atmosphere following an accident, coming into direct contact with the exterior of the containment building (i.e. with peripheral buildings or the environment), due to deterioration of equipment (such as leakage or failure of pipes or equipment on systems that constitute an extension of the third barrier).

Leakage via the secondary shell of the steam generators or the external pressure boundary of the water or steam systems located inside the reactor building is not covered.

\subsection{Behaviour of containment buildings under design-basis conditions}

The reactor building of a facility in the current French fleet comprises:

- either a containment building with a single concrete wall covered with an internal metal sealing liner (900 MWe units);

- or a containment building with double concrete walls (1300 and $1450 \mathrm{MWe}$ units): an inner prestressed concrete wall with no metal sealing liner and an outer reinforced concrete wall. The space between the two walls in maintained below atmospheric pressure by a ventilation system that collects and filters leakage from the inner wall and penetrations prior to its release into the environment (using HEPA filters and iodine traps).

The characteristics of these buildings are specified in Section 2.3.2.3.

It should be noted that the EPR containment building has a double-wall system with dynamic confinement as for the 1300 and 1450 MWe units. In addition, the inside face of the inner wall is covered with a metal sealing liner.

In studying containment leakage, a distinction should be made between:

- leaks via peripheral buildings or via the annulus between the double walls (on 1300 MWe, 1450 MWe and EPR units), for which radioactive substances could either be deposited inside the facility, or be filtered by the filtration devices fitted to the ventilation systems of peripheral buildings or the annulus; these leaks are called "collected" leakage;

- leaks that are directly released into the environment (on $900 \mathrm{MWe}, 1300 \mathrm{MWe}$ and 1450 MWe units); these leaks are called "uncollected" leakage. 
For the EPR, design provisions have been made aiming to "practically eliminate" the possibility of direct leakage into the environment.

\subsubsection{Single wall containment buildings ( $900 \mathrm{MWe}$ reactors)}

Figure 6.1 below shows the various leakage paths from the containment:

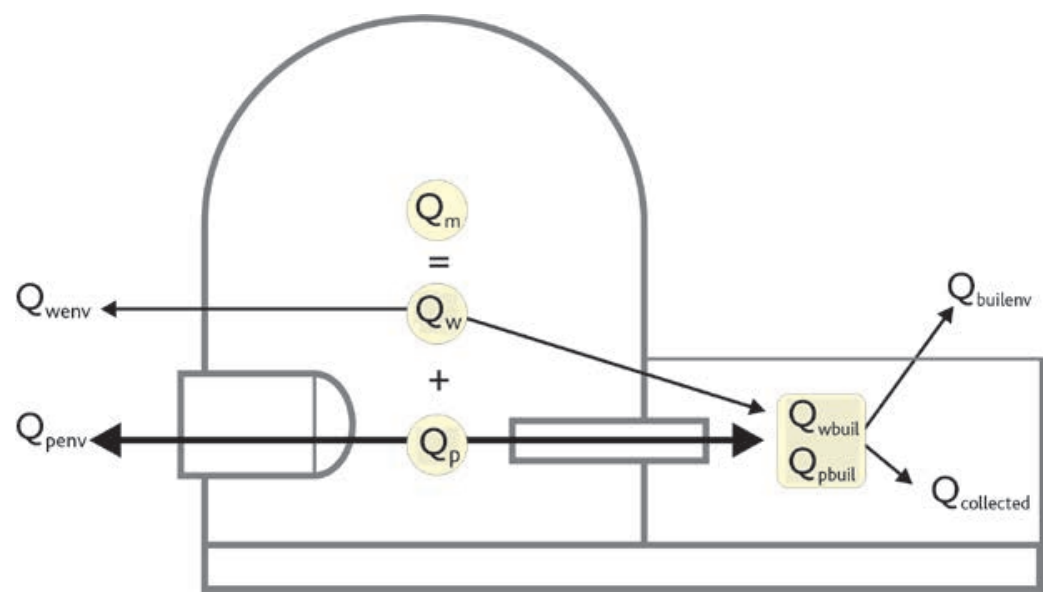

Figure 6.1. The various leakage paths for single containment.

Overall containment leakage $\left(\mathrm{Q}_{\mathrm{m}}\right)$ includes leakage via penetrations $\left(\mathrm{Q}_{\mathrm{p}}\right)$ and leakage via the containment wall $\left(\mathrm{Q}_{\mathrm{w}}\right)$, which is covered by the metal sealing liner over its whole inner surface (including the basemat), i.e.: $Q_{m}=Q_{p}+Q_{w}$.

Leakage via the containment wall or via penetrations can be broken down into two main types:

- leakage collected in buildings with a filtration system (with flowrate $Q_{c}$ ). However, part of the leakage via these buildings (noted $\mathrm{Q}_{\text {builenv }}$ ) could be released into the environment without being filtered, so $Q_{c}=Q_{\text {wbuil }}+Q_{\text {pbuil }}-Q_{\text {builenv }}$ (where $Q_{\text {pbuil }}$ and $Q_{\text {wbuil }}$ are the leaks via penetrations and the wall that are collected in buildings with filtration systems).

- uncollected leakage $\left(Q_{n c}\right)$, which escapes outside the containment without filtration $\left(\mathrm{Q}_{\mathrm{nc}}=\mathrm{Q}_{\text {wenv }}+\mathrm{Q}_{\text {penv }}+\mathrm{Q}_{\text {builenv }}\right)$ and has a predominant impact in terms of radiological consequences $\left(\mathrm{Q}_{\text {penv }}\right.$ and $\mathrm{Q}_{\text {wenv }}$ are direct leaks via penetrations and the wall).

The construction licences for the 900 MWe PWRs state that the containment building must be designed to withstand, without loss of integrity, the loads resulting from an accident consisting of a sudden double-ended guillotine break (i.e. the loss of coolant accident studied in the context of design-basis accidents). Under the conditions of this accident, the containment's maximum leakage rate (via the wall and penetrations) must not exceed $0.3 \%$ per day of the mass of gas inside the containment. 
Given that the metal sealing liner provides good leak tightness, only the containment discontinuities (i.e. the various penetrations) are susceptible to causing a significant increase in containment leakage during an accident.

There are several types of containment penetration:

- penetrations comprising one or more pipes crossing the containment wall;

- penetrations for electrical wiring;

- penetrations for ventilation ducts;

- "reserved" penetrations for possible future pipes or wiring not planned in the initial design;

- containment building basemat penetrations;

- the special penetration for the fuel assembly transfer tube;

- the penetration specially designed for moving large equipment items into or out of the containment building, known as the equipment hatch: IRSN and the operator have paid special attention to equipment hatch leak tightness under accident conditions (see Section 6.3);

- the penetration designed for the personnel airlock.

Containment building penetrations are designed to ensure containment leak tightness under the maximum temperature and pressure conditions inside the containment during normal operation and during reference operating conditions (transients, incidents and accidents).

For example, penetrations for pipes include:

- a double seal barrier system comprising the pipe and the cylindrical carbon steel sleeve containing ${ }^{1}$ it, along with the isolation valves and non-return valves fitted on the pipe inside and outside the containment building;

- a system for periodically measuring their leakage rate (including the isolation valves);

- provisions for periodic testing of automatic isolation valve operation.

These systems are designed to remain leaktight under all the operating conditions mentioned above, and to withstand the loads associated with a line break and the design-basis earthquake. In all cases, containment isolation must be ensured without manual intervention.

1. The carbon steel sleeve is welded to the metal sealing liner inside the containment; it is embedded and anchored into the concrete wall. Penetration leak tightness is provided by:

- the weld between sleeve and sealing liner;

- the sleeve for all its surface inside the containment building;

- the connector between the sleeve and its pipe. 


\subsubsection{Double-wall containment buildings (1300 and 1450 MWe reactors)}

For reactors in the 1300 and 1450 MWe series, containment is provided by a doublewall structure, with:

- dynamic confinement, provided by the annulus ventilation system (AVS), which creates negative pressure in the annulus and recovers and filters leakage from the inner concrete wall; after filtration, leaks are discharged via the nuclear auxiliary building stack;

- static confinement, based on the leak tightness of the inner prestressed concrete wall and the penetrations fitted with seals or with isolation valves on pipes.

Figure 6.2 and the definitions below present the distribution of the various leakage categories for double-wall containments.

The overall containment leakage $\left(\mathrm{Q}_{\mathrm{m}}\right)$ comprises leaks recovered by the $\mathrm{AVS}\left(\mathrm{Q}_{\mathrm{t}}\right)$ and leaks not recovered by this system $\left(Q_{n t}\right)$, i.e.: $Q_{m}=Q_{t}+Q_{n t}$.

Leaks not recovered by the AVS $\left(Q_{n t}\right)$ comprise:

- leakage via penetrations that discharge directly into the external environment (such as the equipment hatch): $\mathrm{Q}_{1 \text { env }}$;

- leakage via the basemat: $\mathrm{Q}_{\text {basemat }}$;

- leaks that arrive in buildings fitted with filtration systems, $Q_{\text {building }}$ part of which may be released into the environment $\left(\mathrm{Q}_{\text {2env }}\right)$.

Leakage not recovered by the AVS can therefore be expressed as follows: $\mathrm{Q}_{\mathrm{nt}}=\mathrm{Q}_{\text {1env }}+\mathrm{Q}_{\text {basemat }}+\mathrm{Q}_{\text {building }}$ where $\mathrm{Q}_{\text {building }}=\mathrm{Q}_{\text {2env }}+\mathrm{Q}_{\text {collected }}$.

Non-collected leaks are $\left(Q_{n c}\right)$ those released into the environment $\left(\mathrm{Q}_{\mathrm{nc}}=\mathrm{Q}_{\mathrm{nt}}-\mathrm{Q}_{\text {basemat }}-\mathrm{Q}_{\text {collected }}=\mathrm{Q}_{\text {1env }}+\mathrm{Q}_{\text {2env }}\right)$; they have a predominant impact in terms of radiological consequences. Containment penetrations that do not discharge into the AVS are therefore sensitive elements.

The licence applications for $1300 \mathrm{MWe}$ and $1450 \mathrm{MWe}$ units specify that:

- the internal leakage rate $\left(Q_{m}\right)$ must not exceed $1.5 \%$ per day of the mass of gas inside the containment under temperature and pressure conditions consistent with an accident involving a sudden double-ended guillotine break - i.e. the loss of coolant accident (LOCA) studied as part of the design-basis accidents;

- the outer containment leakage rate must not exceed $1 \%$ per day of the total mass of gas contained in the volume delimited by the internal face of the outer containment for a negative pressure of 3 mbar in the annulus.

The AVS flowrate is set to ensure that there is a negative pressure of approximately 15 mbar in the annulus under the LOCA conditions cited above. This flowrate means that 


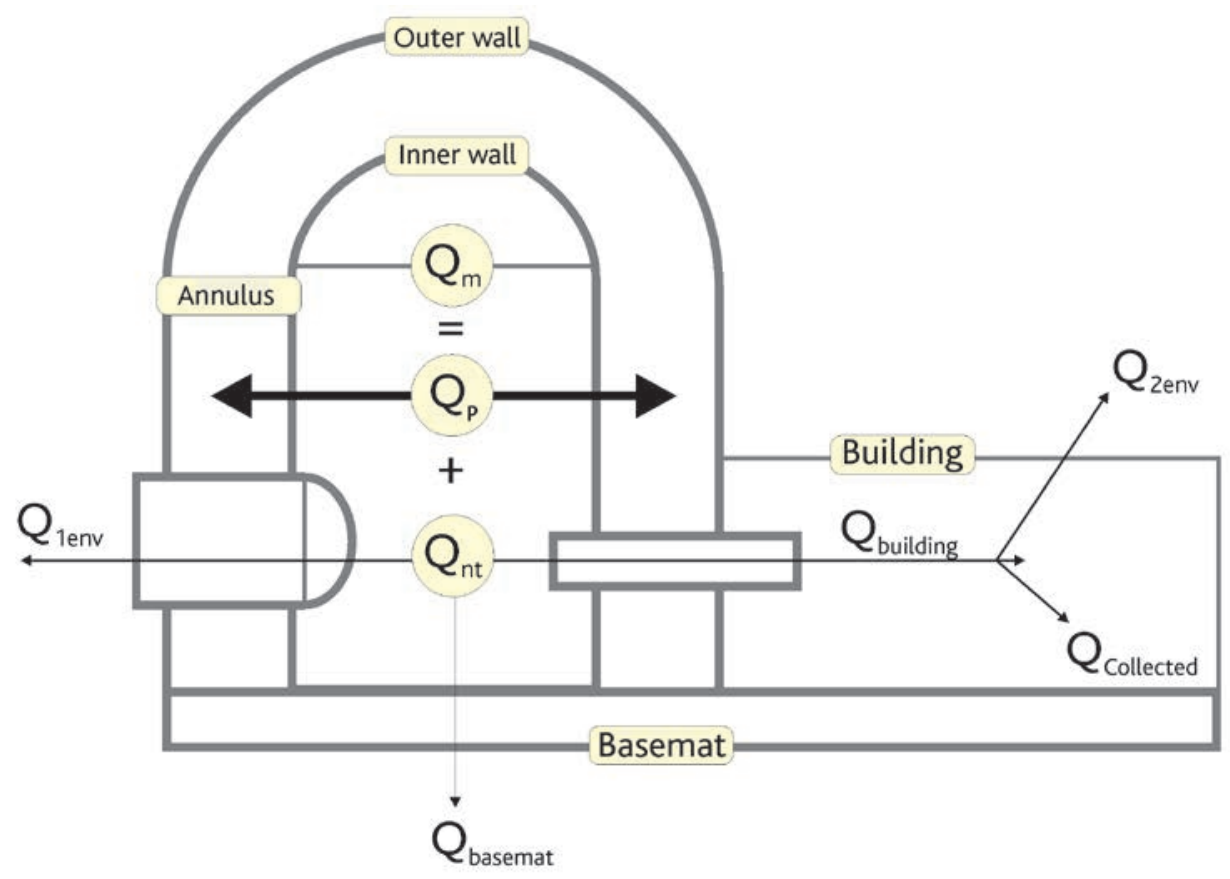

Figure 6.2. Distribution of the various leakage categories for double-wall containments.

negative pressure can be maintained in the annulus under these conditions and prevents any leakage from the annulus to the outside other than via the AVS, for the maximum inner containment leakage rate specified in the license application (see above) and for a windspeed of approximately $120 \mathrm{~km} / \mathrm{h}$ (under these conditions, the negative pressure counteracts the wind suction effect).

Under accident conditions, changes in overall containment leaks and their distribution depend on changes in leaks from the inner containment due to increases in concrete permeability and cracking, on leaks via containment penetrations and also on leaks from the outer containment depending on the collection efficiency of the AVS.

\subsubsection{Double-wall containment on the EPR}

As stated above, for the EPR, design provisions have been made aiming to "practically eliminate" the possibility of direct leakage into the environment.

There must therefore be no direct leakage path from the containment building to the external environment. Pipes that could convey radioactive substances to the outside of the reactor building must lead into peripheral buildings with suitable confinement capacities. Certain buildings around the reactor building, in particular the nuclear auxiliary building, the safeguard auxiliary building and the fuel building, contribute to the containment function (via maintenance of dynamic confinement in these buildings by ventilation and filtration systems for aerosols and iodine). 
The containment design takes into account core melt accidents with low-pressure failure of the reactor vessel. In the event of an accident of this type, containment integrity must be maintained for 12 hours even with no cooling of the containment building.

The following criteria have been adopted:

- the leakage rate of the inner containment must not exceed $0.3 \%$ per day of the gas contained in the inner containment under the accident conditions considered in the design basis (LOCA and core melt accidents);

- the outer containment leakage rate must not exceed $1.5 \%$ per day of the total mass of gas contained in the volume delimited by the internal face of the outer containment for a negative pressure of 6.2 mbar in the annulus (which can compensate for the suction effects of an $80 \mathrm{~km} / \mathrm{h}$ wind).

For accidents considered for the design of the containment including core melt accidents, the AVS must ensure negative pressure in the annulus, and collect and filter leakage from the inner containment which is subject to overpressure due to the accident.

\subsubsection{Monitoring the integrity and leak tightness of containment buildings}

After the first two "barriers", confinement of radioactive substances is ensured by the integrity and leak tightness of the containment building and its penetrations under the various temperature and pressure conditions considered.

The containment is subjected to:

- mechanical resistance pressure tests;

- two types of leak tightness tests:

- overall tests by pressurising the containment;

- partial tests by local pressurisation of penetrations and isolation systems.

\subsubsection{Mechanical resistance test}

\section{Initial pressure test}

Prior to reactor commissioning, the reactor building is subjected to a mechanical resistance test performed by gradually pressurising the containment up to the test pressure at ambient temperature. Measurements provided by mechanical monitoring devices are recorded during containment pressurisation and depressurisation.

For $900 \mathrm{MWe}$ reactors with a metal sealing liner, the test pressure used is 1.15 times the design pressure of the containment, to take into account the thermal thrust of the metal sealing liner in the event of LOCA. 
For the EPR inner containment, which also has a metal liner, this thrust leads to using an initial test pressure of 1.10 times the design pressure.

The test pressure is the design pressure for reactors without a metal sealing liner (1300 MWe and 1450 MWe reactors of the P4, $\mathrm{P}^{\prime} 4$ and N4 series).

\section{Periodic tests}

After the initial pressure test, the containment is subject to mechanical tests at the design pressure during the pre-service inspection and during each of the ten-yearly outage programmes. Measurements provided by mechanical monitoring devices are recorded during containment pressurisation and depressurisation.

Monitoring measurements performed regularly during operation are used to track delayed deformation of the unpressurised structure (concrete shrinkage and creep).

\subsubsection{Leak tightness tests}

\section{- Overall containment leak tightness tests ("type A" tests)}

The purpose of overall leak tightness tests is to measure the overall leakage rate for containment buildings with a metal liner ( 900 MWe reactors and the EPR) and the leakage rate of the inner containment and its components for double-wall reactors without a metal liner (1300 MWe and 1450 MWe reactors). They are performed at the end of construction, i.e. as pre-operational tests prior to first core loading, then every ten years.

Overall leak tightness tests are performed at the design pressure of the containment.

Leakage flowrates are determined by measuring the dry air pressure in the containment (corrected for the partial pressure of water vapour obtained by hygrometer measurements), by measuring the temperature at various places inside the containment and by applying the ideal gas law: variation of the quantity PV/T over time indicates the loss of mass over time and therefore the leakage rate, which is defined as the ratio of the mass of air escaping from the containment in 24 hours to the total mass of air under pressure in the containment.

The leakage rate (including uncertainties) is compared with the criterion, which is $0.162 \%$ per day for reactors with a metal liner ( $900 \mathrm{MWe}$ reactors and the EPR) and $1.125 \%$ per day for the inner containment of reactors with double-wall containment with no metal liner (1300 MWe and 1450 MWe reactors).

\section{Overall leak tightness tests on the outer containments of $1300 \mathrm{MWe}$ and 1450 MWe reactors, and the EPR.}

An overall leak tightness test on the outer containment and its penetrations is performed during tests of the AVS, prior to "type A" overall tests. 
Essentially, this test is performed by using the AVS to put the annulus under negative pressure (compared with atmospheric pressure) and then measuring the flowrate discharged by this system, which is equal to the flowrate entering the annulus.

For $1300 \mathrm{MWe}$ and $1450 \mathrm{MWe}$ reactors, the acceptability criteria for this test is that the measured flowrate be less than $1 \%$ per day of the mass of air in the space delimited by the inner wall of the outer containment for a negative pressure of $3 \mathrm{mbar}$ in the annulus.

\section{Partial leak tightness tests for penetrations into the reactor building}

Partial leak tightness tests are performed for penetrations into the reactor building (into the containment wall for $900 \mathrm{MWe}$ reactors and into the inner wall for $1300 \mathrm{MWe}$ and $1450 \mathrm{MWe}$ reactors and the EPR) to detect and measure local leaks that may affect certain penetrations and associated isolation valves. These tests are subdivided into "type B" and "type C" tests.

The "type B" tests cover:

- "electrical" penetrations (including those for the airlocks);

- sealing systems on personnel airlock doors, including penetrations for door controls;

- the equipment hatch sealing system;

- penetrations fitted with removable blind flanges with seals (in particular, the penetration used for fuel transfer).

The "type C" tests cover isolation valves on pipes that penetrate the containment, other than those subject to "type B" tests and other than those of the secondary systems, which are considered to be closed systems within the containment, maintained above the pressure of the containment atmosphere.

Leak tightness tests for sections of systems outside the containment that may carry contaminated fluids out of the containment during accidents involving failure of the first two barriers (extensions of the third barrier, see Section 6.1).

For reactors in the current French fleet, this concerns the safety injection system (SIS), the containment spray system (CSS) and the containment atmosphere monitoring system (ETY).

Leak tightness tests on the sections of the SIS, CSS and ETY systems outside the containment are performed at the same frequency as overall leak tightness tests. 


\subsection{Mechanical behaviour of containments in the event of a core melt accident}

\subsubsection{Introduction}

During a severe accident, the containment building of the concerned reactor may be subject to several types of load that exceed the temperature and pressure conditions adopted for its design. These loads would be induced by the physical phenomena described in Section 5.1 to 5.3, which occur during different phases of core degradation, in particular possible combustion of hydrogen produced during degradation of fuel rod cladding or during reflooding of the degraded core, a vapour explosion inside or outside the reactor vessel, and the slow pressure increase in the containment during the interaction between the corium and the basemat concrete.

Extensive research has been performed and is underway to understand the behaviour of containment buildings on French reactors under the effect of such loads, outside the design basis of the containments. The approach differs depending on the type of containment building, but the objective is the same, as it ultimately involves determining the leakage flowrate from the containment to the environment beyond the temperature and pressure conditions adopted for its design.

The problem is complex and solving it requires sophisticated mechanical studies, in particular involving theoretical assessments of containment stresses and strains, supplemented by experimental studies to confirm the theoretical assessments. R\&D work is also needed, in particular regarding the cracking of concrete subject to loads corresponding to a core melt accident. On this subject, EDF has undertaken significant experimental and theoretical work (see the MAEVA Model described in Section 6.3.3.2 and Reference [1] respectively), which mainly applies to the double-wall containments of 1300 MWe reactors.

IRSN has also performed studies to support the Level 2 Probabilistic Safety Assessments (PSA2) for the $900 \mathrm{MWe}$ and $1300 \mathrm{MWe}$ reactors.

As an example, a relatively detailed overview of these studies and the results obtained is given in Section 6.3.2 for the containments of 900 MWe reactors. IRSN has also developed studies for the containments of $1300 \mathrm{MWe}$ reactors. The approach used for the simulations concerning this type of containment is described in Section 6.3.3.

\subsubsection{Mechanical behaviour of the containments of $900 \mathrm{MWe}$ PWR power plants}

The studies undertaken were based on simulations using nonlinear finite element methods. Models representing the containment at different scales were constructed so that the behaviour of the containment at different levels of detail could be understood (this is called a multi-scale approach), making a distinction between the containment wall, the equipment hatch area and its cover. This approach meant that the various 
thermo-mechanical phenomena could be reproduced realistically, while maintaining reasonable times and simulation costs.

A sequence of mechanical simulations were performed using meshes suitable for the level of detail desired for the modelling: complete overall model of the containment building, quarter containment model, local model of the equipment hatch penetration, see References [3] and [4]. However, it was first necessary to specify bounding profiles for the loads to which the containment building would be subjected during a core melt accident.

\subsubsection{Selection of the core melt accident scenarios used in the studies (increases in temperature and pressure in the containment)}

The purpose of the mechanical studies performed by IRSN as part of the level 2 PSA for 900 MWe PWR power plants was to assess the response of the containment building to pseudo-static loads, corresponding to a pressure peak or to a slow rise in pressure, see Reference [1].

Linear calculations, performed for several core melt accident scenarios, were used to determine the scenario leading to the most severe degradations of the containment building. This is the "AF scenario", which has three phases (see Figure 6.3):

- a thermal pre-loading phase corresponding to core degradation; times P1 and P2 on Figure 6.3 correspond to the beginning and end of this phase respectively;

- the temperature and pressure peak corresponding to adiabatic isochoric combustion of the hydrogen produced by oxidation of core materials; time P3 on Figure 6.3 corresponds to the peak;

- a phase of slowly rising temperature and pressure, corresponding to the moltencore concrete interaction $(\mathrm{MCCl})$ with the corium coming into contact with water from the containment sump; a large quantity of hot gases is produced during this interaction, which causes rising temperature and pressure in the containment; times P4 and P5 on Figure 6.3 correspond to the beginning and end of this phase respectively; P5 has been set to a pressure assumed to be above the maximum resistance pressure of the containment.

A prior parametric study performed for various values of the temperature and pressure peak at time P3 produced a pressure peak value of approximately 11.4 bar abs. (i.e. about 2.3 times the design pressure of the containment). This pressure corresponds to that produced by the adiabatic isochoric combustion of $125 \%$ of the maximum quantity of hydrogen produced by core oxidation. Selection of the extreme temperature and pressure values of the AF scenario provides a margin for the mechanical loads on the containment for the core melt accident scenarios covered in the IRSN level 2 PSA. Furthermore, with the aim of quantifying the thermal effects of the accident on the mechanical behaviour of the containment, the AF scenario includes two different temperature rise kinetics (see Figure 6.3): one at time $\mathrm{P} 3$, corresponding to a rapid rise in containment temperature, and the other between times P4 and P5 ( $\mathrm{MCCl}$ phase), corresponding to a 


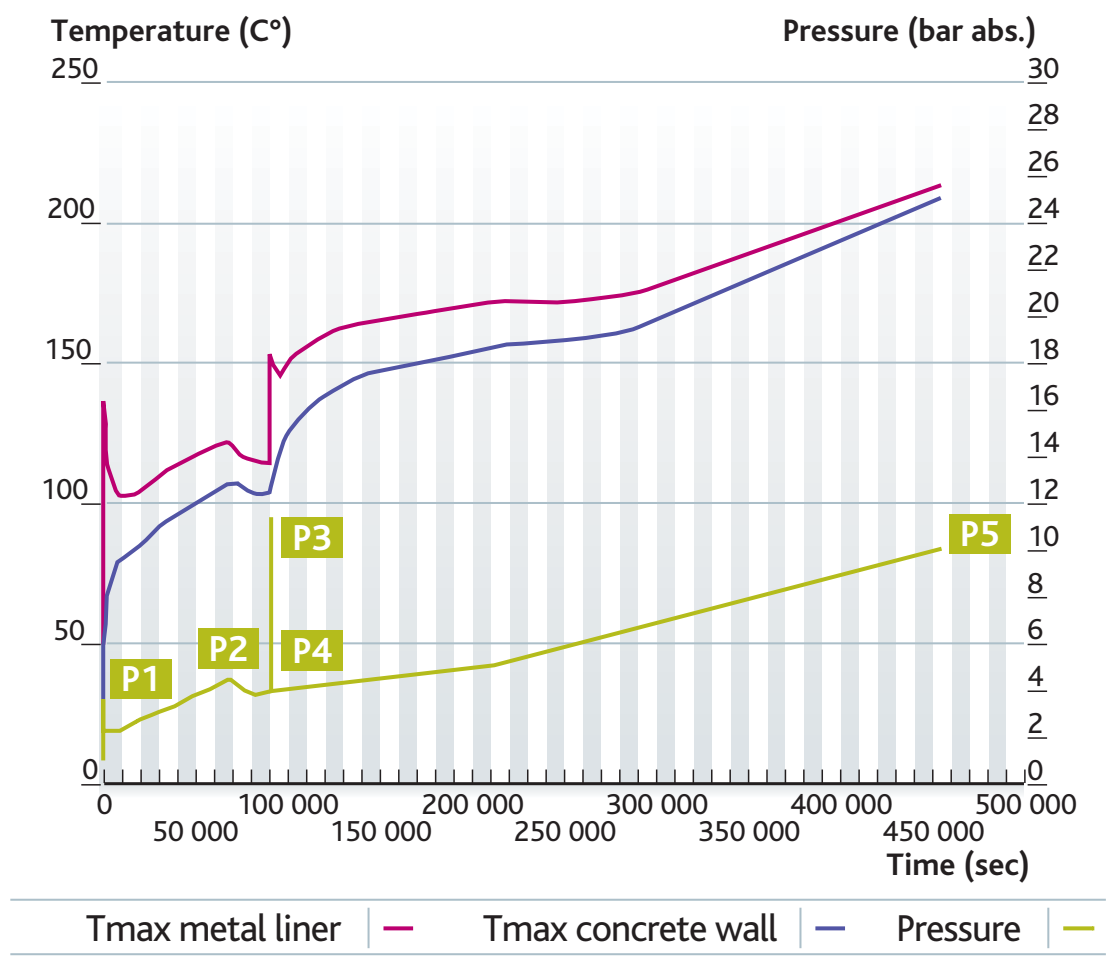

Figure 6.3. Changes in containment temperature and pressure for the AF scenario.

slow temperature rise. This gives the possibility of extrapolating the results of the study performed to other core melt accident scenarios, with different containment temperature change profiles.

\subsubsection{Complete overall model of the containment building (simulation of the initial state of the containment)}

Simulation of the behaviour of the containment building during an "AF" core melt accident scenario requires the most realistic possible knowledge of the state of the structure prior to the accident under the effects of shrinkage and creep phenomena. The age of the containment was taken to be 30 years. A simulation of prestress and creep to determine the state of the structure at 30 years was performed for a containment representative of a 900 MWe PWR power station. This simulation, whose geometrical modelling and mechanical loads are described below, served as a basis for all the simulations performed with the various models described in Sections 6.3.2.3 to 6.3.2.5.

The position and tensioning of prestressing tendons was not sufficiently symmetrical to avoid performing the simulation over the whole containment $\left(360^{\circ}\right)$. 
The mesh used reproduced the various containment components: wall concrete, passive reinforcements, metal liner, protective concrete on the basemat, and a simplified model of the equipment hatch penetration with sleeve, flanges and cover. All prestressing tendons, their geometry and their deviations were modelled with precision, in particular around the equipment hatch and the two personnel airlocks. The model also reproduced the effects of the ground and backfill. The images in Figure 6.4 (first left) and Figure 6.5 present the meshes used.

The concrete containment was subject to its own weight and to the prestress of the tendons, simulated taking into account the various phases of tensioning, the various causes of loss of tension (friction, retreat of anchoring heads etc.) and the geometrical specifics of all tendons.

Concrete shrinkage and creep were estimated, during tendon tensioning and over a period of 30 years, using the formulae in French Regulations (BPEL 1999). They were introduced at each step in the simulation in the form of a standard "initial strains"

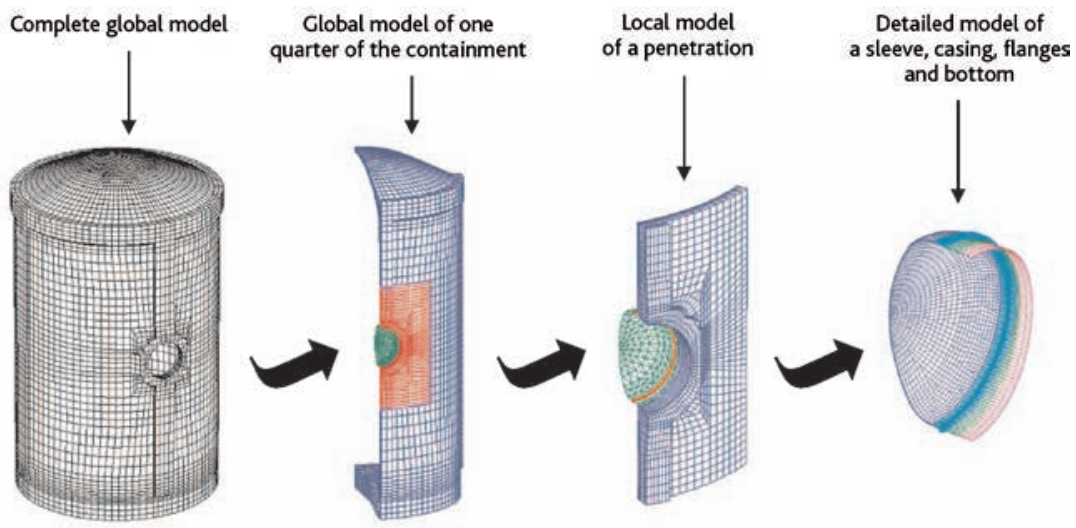

Figure 6.4. Nested models used: complete overall model, overall quarter containment model, local model of a penetration, detailed model of sleeve/penetration/flanges/cover.
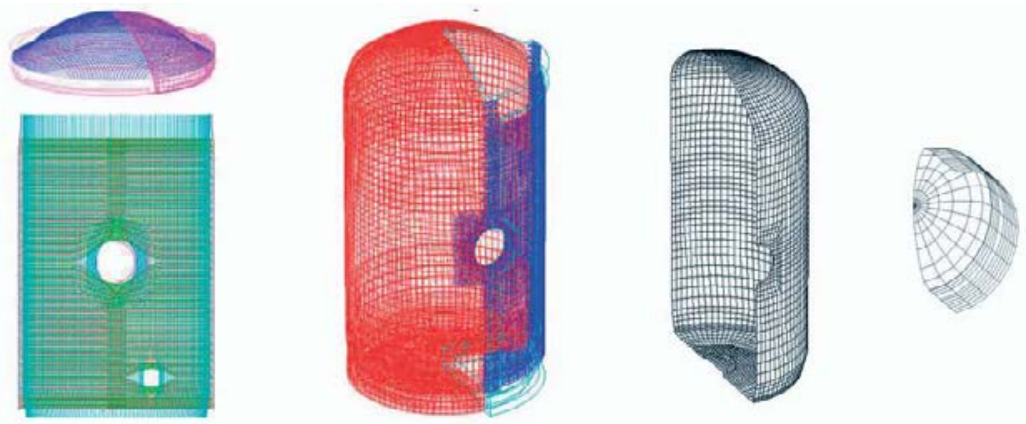

Figure 6.5. Mesh representing the prestressing tendons, passive reinforcements, metal liner, and equipment hatch used for the complete overall model. 
loading, based on the drying characteristics of the concrete, the age of the loading and the stress field.

The delayed behaviour of the containment simulated using finite element methods was compared with the results of monitoring measurements performed by EDF at 20 years, which meant that the parameters in the BPEL formulae could be adjusted with respect to the results of these measurements.

\subsubsection{Quarter containment model}

The thermo-mechanical simulation of containment behaviour under the conditions of the "AF" core melt accident scenario was performed using a mesh representing a quarter of this containment to reduce simulation times.

The simulation of prestress and creep performed using the complete model of the containment was used for the quarter containment model, prior to applying the temperature and pressure loads due to the core melt accident.

As for the complete model, the quarter containment model represented the containment concrete, prestressing tendons, passive reinforcements, metal liner, protective concrete laid on the basemat, internal structures, and the equipment hatch penetration with its sleeve, flanges and cover. Figure 6.4 shows the mesh used for this simulation.

The finite element model for the concrete used linear eight-node solid elements with a nonlinear behaviour law that took into account uniform volume cracking of the concrete (using the Ottosen Fictitious Crack Model for the rheology). The finite element model for prestressing tendons and passive reinforcements used two-node bar elements with an isotropic strain-hardening nonlinear behaviour law. The finite element model for the metal liner used shells with an isotropic strain-hardening nonlinear behaviour law. The ground was simulated using a single element extending beyond the horizontal surface of the basemat, which allowed for basemat uplift depending on the loads due to the core melt accident, see Reference [4].

\subsection{Analysis of the results of simulations performed using the "quarter containment" model}

Analysis of the results of the simulations for the core melt accident studied leads to the following observations:

- the simulations confirm the locations of the most sensitive areas on the containment building, in particular the equipment hatch and the gusset area (see Figure 6.6) which presented through-wall cracks in relation with the tendon gallery;

- comparison of the results of simulations for the AF scenario and those obtained for the scenario without pressure peak P3 shows that this peak has little effect on the later behaviour of the containment building (containment displacements are pseudo-reversible in the main body during the pressure peak); 

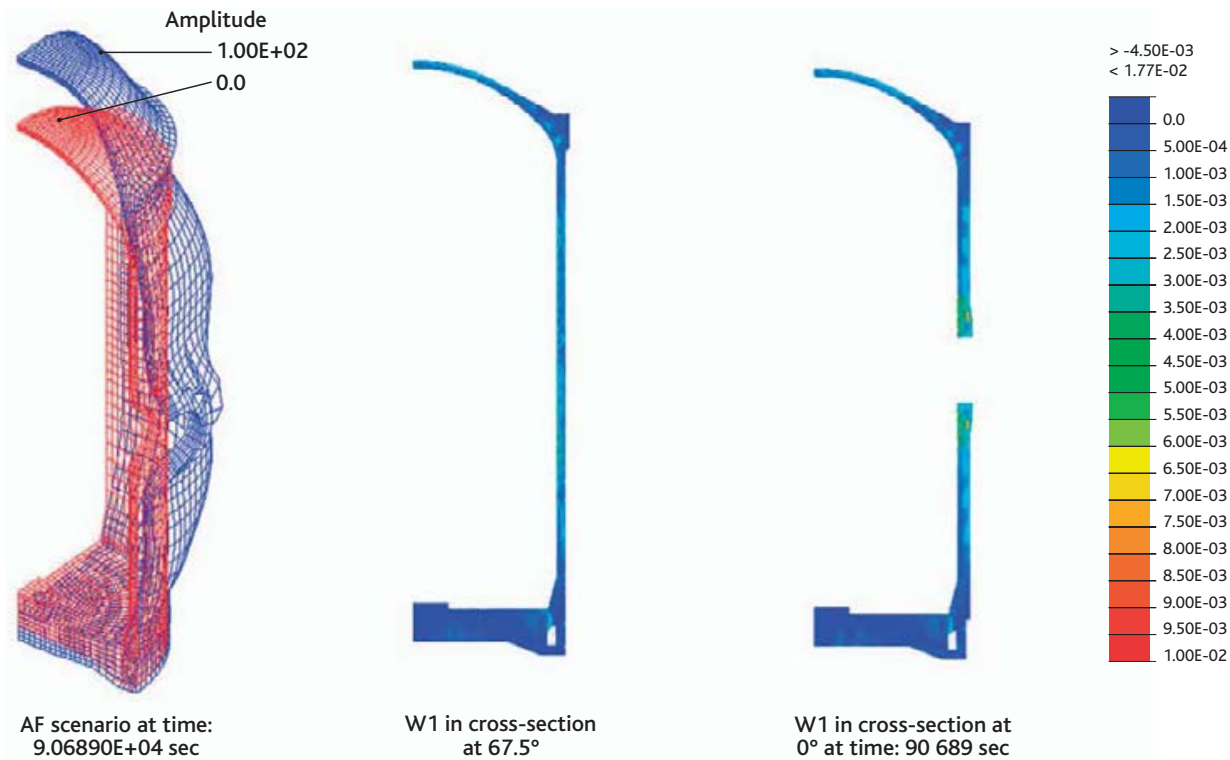

Figure 6.6. Containment strain amplified 100 times and concrete cracks, in the equipment hatch axis and the main body, at the pressure peak of the AF scenario (time P3).

- overall stability of the structure is provided by the integrity of the prestressing tendons;

- the maximum equivalent plastic strain of the metal liner just after the pressure peak (time P4 on Figure 6.3) is greater than during the pressure peak itself (time P3 on Figure 6.3);

- the mechanical behaviour of the containment can be extrapolated to other scenarios because the results of the simulations show that the mechanical phenomena depend mainly on the pressure;

- possible tears in the metal liner and cracks in the prestressed concrete wall constitute leakage paths;

- the strains calculated for the metal liner remain well below the breaking strain of steel; according to the modelling results, there should not be any tearing of the liner and containment building leak tightness should be maintained.

Analysis and interpretation of the results of the studies described above required recourse to experimental results, in order to define acceptability criteria for the results of the nonlinear simulations performed, so that the risk of containment failure (i.e. of the metal liner or prestressed concrete wall) could be estimated on the basis of the strains observed. To achieve this, the results of the simulations were compared with certain experimental results obtained on scale models, in particular the prestressed concrete containment vessel (PCCV) model used by the American-Japanese programme (NUPEC - NRC - Sandia) described in the following section. A group of 
experts was involved in this comparison between simulations and experiments with the aim of specifying these criteria.

\subsection{Analysis of the test results on the scale model}

Recourse to test results representative of the problem studied is an important aspect for validation of the simulations performed using the CAST3M code for mechanical simulations. The difficulty is in finding tests that are representative of the load conditions under consideration, see Reference [5].

The PCCV model is a 1/4-scale representation of a prestressed concrete containment building with a metal liner. Sandia National Laboratories performed pressure tests on the model with dry air at ambient temperature. These were followed by a destructive test on the containment (to understand its ultimate behaviour).

The tests performed on the PCCV model demonstrated the existence of tears in the metal liner leading to significant leaks for a pressure of around 10.7 bar abs. (which is 2.5 times the design pressure of the model, see Reference [6]).

Analysis of the results of tests performed using this model and of computer modelling of these tests was performed as part of International Standard Problem 48 (ISP48) organised by the OECD, in which IRSN participated. Simulations were run on CAST3M using the same approach as in the simulations for the level 2 PSA project, see Reference [6].

The simulations performed by IRSN and the various teams involved in this comparison did not predict the tears observed at a pressure of 10.7 bar abs., even when taking the various geometrical discontinuities into account, see Reference [7].

For this containment pressure, the circumferential strain measured on the metal liner in the main body was $0.17 \%$ and the calculated equivalent plastic strain was around 0.3 to $0.5 \%$. The same order of magnitude for the strain was obtained by the simulations. However, this value is lower than the breaking strain (of the order of 10\%) obtained during liner characterisation tests performed after the tests on the scale model.

In order to reproduce the tears in the metal liner, which are a local phenomenon, the computer models used must be at the scale of this phenomenon taking into account the discontinuities constituted by the various welds and liner embedments and by any cracks created in the concrete, by using codes that can simulate strain localisation and tearing of the metal liner.

This difficulty in interpreting the results of the tests performed on the PCCV model led IRSN to call on the group of experts mentioned above. The purpose of this group was to advise IRSN on the best way to use the test results in their application to simulations of containment buildings performed as part of the IRSN level 2 PSA project. At the end of its consultations, the group proposed the following application criterion: the maximum plastic strain in the main body of the metal liner obtained by nonlinear simulations of the main body must be less than $0.30 \% \pm 0.15 \%$. Beyond this value, tearing of the metal liner is highly likely due to strain localisation. This localisation 
effect concentrates the strain at a point in the structure where the strain will exceed the tearing criterion for the material.

A strain value of $0.3 \%$ for the metal liner corresponds to a containment pressure of around 10.5 bar abs. for the AF scenario, which would suggest that the pressure that would lead to containment failure is approximately 10 bar abs. (i.e. twice the design pressure of the containment building).

It should be noted that the breaking strength of the penetrations has not been considered in this study.

\subsubsection{Local model of the equipment hatch penetration}

Modelling of a quarter containment, with its prestressing tendons and passive reinforcements, using nonlinear mechanical behaviour laws, requires considerable simulation time, despite relatively coarse spatial discretisation of the geometry. A more specific model was therefore used to study the behaviour of the sensitive areas, such as the equipment hatch, in particular with regard to the risk of separation of the flanges that make up the hatch closure system (such a separation would lead to direct leakage into the environment). This modelled the precise geometry of the flanges and the bolts that keep them together. This local model included the same components as the overall model (the concrete, metal liner, passive reinforcements and prestressing tendons making up part of the 10.60-m-wide and 23.40-m-high cylindrical containment, with the equipment hatch sleeve, flanges and bolts, gussets and anchoring collars in the concrete etc.). The same thermo-mechanical loads and the same material behaviour laws were applied to this local model, along with the prestressing, creep and shrinkage of the concrete used in the overall model.

Several simulations were performed for the penetration, on the basis of the same quarter containment simulation, by modifying certain parameters such as the mechanical characteristics of the bolts, passive reinforcements, mesh, boundary conditions and bolt tightening. These sensitivity studies provide insight into the uncertainties due to the model, the simulations and the materials, which are around $15 \%$.

The flanges were modelled using shell elements, as were the liner, the gussets, the collars and the sleeve/penetration/flanges/cover assembly. Rebars and tendons, and the 44 bolts used to close the equipment hatch were modelled using two-node bar elements (see Figure 6.7). Three types of bolt were considered: the bolts originally used for the containments of 900 MWe PWR power plants (33 mm diameter; yield strength $238 \mathrm{MPa}$ ) and two other types of bolt that are considered stronger (33 mm diameter; yield strength $729 \mathrm{MPa}$, and $24 \mathrm{~mm}$ diameter; yield strength $852 \mathrm{MPa}$ ).

Over the scope of the local model, the displacement fields obtained using the quarter containment simulation were used as boundary conditions for the local model for each time step. The validity of this method was checked, in particular by comparison of the results obtained with local models of different scales. 


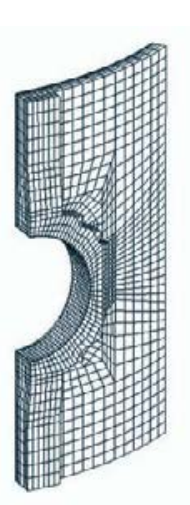

Penetration 7164 mds 5676 elts

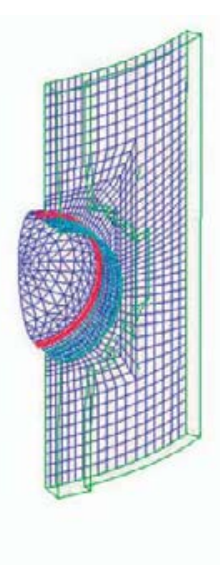

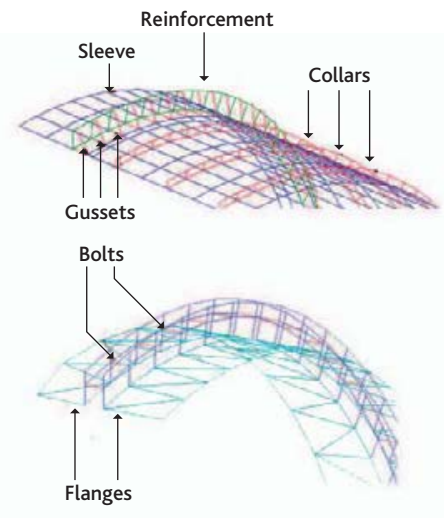

Figure 6.7. Concrete penetration (a), liner/sleeve/flanges/cover (b), tendons (c), sleeve detail (d), details of flanges and bolts (e).

In the absence of experimental data regarding the mechanical behaviour of seals subject to ageing, the studies performed do not take into account the presence of the seal between the two flanges, and only provide the separation between flanges as the result. The main results obtained were as follows:

- the choice of bolts (characterised by their diameter and the yield strength of the steel) is the critical parameter of the mechanical study, with major repercussions on the amplitude of flange separation;

- the temperature and pressure peak (time P3) has relatively little effect on the value of separation as a function of pressure. Flange spacing is therefore mainly conditioned by buckling and ovalisation of the containment around the equipment hatch sleeve, which are not very temperature sensitive;

- regardless of scenario, flange reclosure is only partial after the pressure drops. This is due to plastification of the bolts and irreversible deformations of the concrete containment around the equipment hatch penetration;

- flange separation is approximately constant around the circumference of the sleeve, with an opening length of around $4 \mathrm{~m}$ (for the half-circumference). The leakage cross-section is more or less proportional to maximum flange separation.

\subsubsection{Detailed model}

Modelling the flange connection is one of the most complicated aspects of the thermo-mechanical study, and the most sensitive in terms of flange separation. In the local model, use of shell elements leads to overestimating flange separation. This was the motive for producing a detailed model with the following main characteristics:

- solid elements were used to model the metal sleeve, flanges, bolts and hemispherical hatch cover, in order to overcome the difficulties associated with specifying the boundary conditions when using shell or bar elements; 
- the mesh was much finer meaning that the real geometry could be more faithfully reproduced (changes in thickness, weld grooves etc.);

- the gussets, collars, concrete and passive reinforcements were not represented in the model. It was assumed that the concrete imposes its displacements and deformations onto the metal parts which are less rigid.

The behaviour laws used were identical to those used for the penetration simulation. Due to symmetry, the mesh used represented a half-circumference (see Figures 6.8 and 6.9).

The detailed model was implemented in a similar way to the local model. The displacement boundary conditions applied were those resulting from the local model simulation. They were applied to the scope of the detailed model. The detailed model with its solid elements and more precise representation of the flanges, spacers and clamps provides better understanding of the behaviour of the closure system. In particular, it brought to light the predominant effect of shear loads on the bolts up to their failure, for moderate pressures in the containment building, with a significant risk of loss of hatch cover leak tightness.

This model therefore demonstrated:

- the complexity of the flange strain mechanisms, excluding any possibility of extrapolation from simplified models, and the strong coupling between flange buckling and ovalisation phenomena;

- the weak effect of axisymmetric loads, from the concrete via the sleeve, on flange separation and bolt shear (loads due to pressure in the containment building, and sleeve pinching under the effect of the prestressed compression imposed in the concrete by tendon tensioning) and the importance of non-axisymmetric strain imposed on the sleeve by the containment building, responsible for flange buckling and ovalisation;

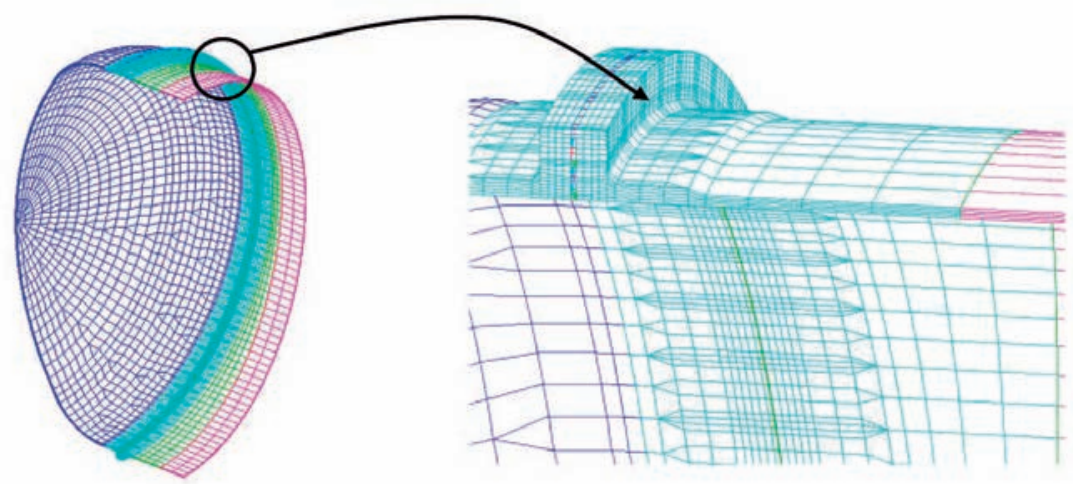

Figure 6.8. Mesh for the whole sleeve and the flange on the hatch cover side (with spacers and bolts). 

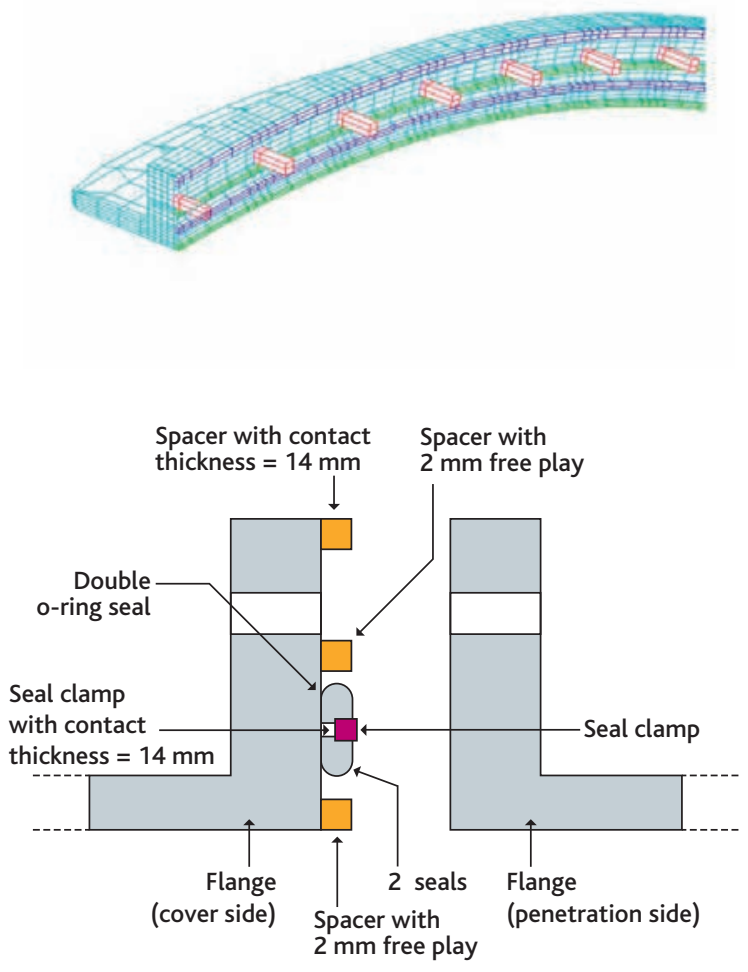

Figure 6.9. Mesh for a flange (with spacers, clamp and bolts) and cross-sectional diagram of the flanges.

- the importance of the choice of bolts (in particular, their diameter and yield strength of the steel), which are subject to shear loads;

- the influence of the free play between bolts and flanges.

With regard to this last point in particular, if the free play between flanges and bolts was not taken into account, the results showed that the bolts plastic yielded at low pressures (between 3.2 and 5.5 bar abs. depending on the bolts selected) if the two flanges were free to slide with respect to each other. These low values, due to bolt shear, were strongly sensitive to the free play between bolts and flanges.

During hydrogen combustion, the margin with respect to shear provided by around $3 \mathrm{~mm}$ of free play, which is acceptable with regard to the risk of the bolts yielding, led to irreversible separation of the flanges from pressures of between 6.2 and 8.5 bar abs. depending on the bolts selected. It would appear that reducing the diameter of the bolts is detrimental to their tensile strength, while increasing their yield strength improves their mechanical shear strength. 


\subsubsection{Mechanical behaviour of the containments of $1300 \mathrm{MWe}$ PWR power plants}

\subsubsection{Approach used in the mechanical studies}

The objective for this type of containment is similar to that of the mechanical studies performed for the containment of a 900 MWe PWR. It involves determining the leak tightness limit of the containment building under the thermal and mechanical loads to which this containment is subject during a core melt accident. However, a different approach is used for two key reasons:

- the internal face of the inner containment does not have a metal liner. The purpose of mechanical studies is therefore to determine the ability of the prestressed concrete of the inner containment to maintain confinement under various accident loads;

- leakage from the inner containment appears in the annulus. This space is normally under negative pressure and the gases and aerosols extracted by the annulus ventilation system (AVS) are filtered before discharge. Mechanical studies, as described above, must therefore be supplemented by an examination of possible failures of this system and of the outer containment during a core melt accident, taking severe weather conditions into account (in particular strong winds).

IRSN has performed studies regarding these containments in support of its Level 2 Probabilistic Safety Analysis (PSA2) for 1300 MWe PWR power plants. These studies also support assessment of the studies submitted by EDF as part of the third ten-yearly outage programme for 1300 MWe PWR power plants, in particular studies concerning the management of core melt accidents, bearing in mind that EDF is developing its own studies on this subject. One of the specific difficulties that appeared in the level 2 PSA quantifications and during technical discussions with the operator, is the assessment of leakage via the prestressed concrete wall of the inner containment when under pressure, an assessment which affects the quantity of releases of radioactive substances into the annulus and the ability of the AVS to maintain this space below atmospheric pressure. Difficult questions need to be answered to obtain this quantification, in particular:

- understanding of concrete cracking (crack spacing, opening, length, etc.) on the basis of the mechanical stress states in the containment walls. The formulae in French Regulations that apply to concrete shrinkage and creep provide values that are very different from those measured. On this subject, EDF has launched a national study project (the CEOS project) in which IRSN is participating. Results of research actions performed under this project and their analysis are expected this year;

- quantification of leakage via a network of intercommunicating cracks which are not necessarily themselves through-wall cracks. IRSN has studied this question as part of the ECOBA project regarding the containment properties of reinforced concrete structures, funded by the French National Research Agency (ANR). Results of research actions performed under this project and their analysis are expected this year. 
Given the difficulties stated above and awaiting the results of the aforementioned projects, a semi-empirical approach is used in IRSN studies. The steps of this approach can be summarised as follows:

- the degree of cracking of the inner containment wall is simulated using CAST3M code, using a finite element model of this wall based on the prestress in the tendons, and concrete shrinkage and creep;

- the results of these simulations are adjusted using experimental results obtained during containment pressure tests at design pressure (in particular, concrete cracking measurements are performed following these tests);

- the adjusted model is then validated by comparing the results with those of experiments performed on scale models under conditions similar to those of a core melt accident (see the description of MAEVA tests in Section 6.3.3.2);

- the validated simulation model, performed using CAST3M code, is then applied to the inner containment of a $1300 \mathrm{MWe}$ PWR assumed to be subject to the temperature and pressure loads of a core melt accident deemed adequately bounding.

Completion of these various steps should allow estimates of releases into the annulus to be made this year.

It should be noted that experience feedback on pressure tests performed at design pressure and the results of the initial simulations regarding the mechanical behaviour of 1300 MWe PWR containments show that the concrete of the inner containment does not remain in compression everywhere but has areas in traction that could crack. Furthermore, given the delayed deformations of prestressed concrete, the prestress reduces over time, which increases the extent of the areas that may be found in traction. The areas involved (along with those where concreting faults were observed during the pressure tests) have been covered with a coating to restore leak tightness, in compliance with the leakage rate requirements.

In parallel, IRSN performed a study of the various possible failures of the AVS under core melt accident conditions, in the context of studies to support its level 2 PSA. The purpose was to determine the operating limits of the ventilation system (i.e. its ability to maintain the annulus below atmospheric pressure), its filtration systems, and iodine traps which are very sensitive to the humidity.

\subsubsection{Experiments performed to support mechanical studies for 1300 MWe PWRs: MAEVA tests}

In 1994, EDF decided to produce a scale model of a containment building, in order to study the mechanical resistance of the containment buildings of French reactors. The scale model represents the main wall of the inner containment at a scale of 1/3 for diameter and $1 / 1$ for wall thickness. The annulus is also represented but the concrete outer containment is replaced by a metal wall on the model (see Figure 6.10). EDF's objective was to perform an experimental study of the thermo-mechanical behaviour of the prestressed concrete inner containment for design-basis and beyond-design-basis conditions. 
More precisely, the main objectives of the tests were as follows:

- study of heat transfer in a prestressed concrete wall in the presence of a mixture of air and steam;

- study of the behaviour of a prestressed concrete wall under beyond-designbasis conditions, by subjecting the model to scenarios of rising temperature and pressure;

- assessment of air and steam leakage rates under accident conditions by comparison with those measured with dry air during pressure tests;

- study of the behaviour of composite-material coatings for the pressure test sequences and the various accident scenarios, and validation of their implementation conditions at industrial scale.

The results should enable assessment of the ability of the inner containment to provide the confinement function under design-basis and beyond-design-basis accident conditions, and specification of the margins on the leakage rates with respect to pressure test conditions.

The MAEVA scale model consisted of a cylindrical prestressed concrete wall, $16 \mathrm{~m}$ in diameter, $1.2 \mathrm{~m}$ thick and $5 \mathrm{~m}$ tall (see Figure 6.10). It was built on the Civaux site, using high-performance concrete with the same characteristics as the concrete used for the containment on Unit 2 of the Civaux power plant. The upper slab was supported by four prestressed concrete pillars located in the four quadrants of this slab. The inner wall was

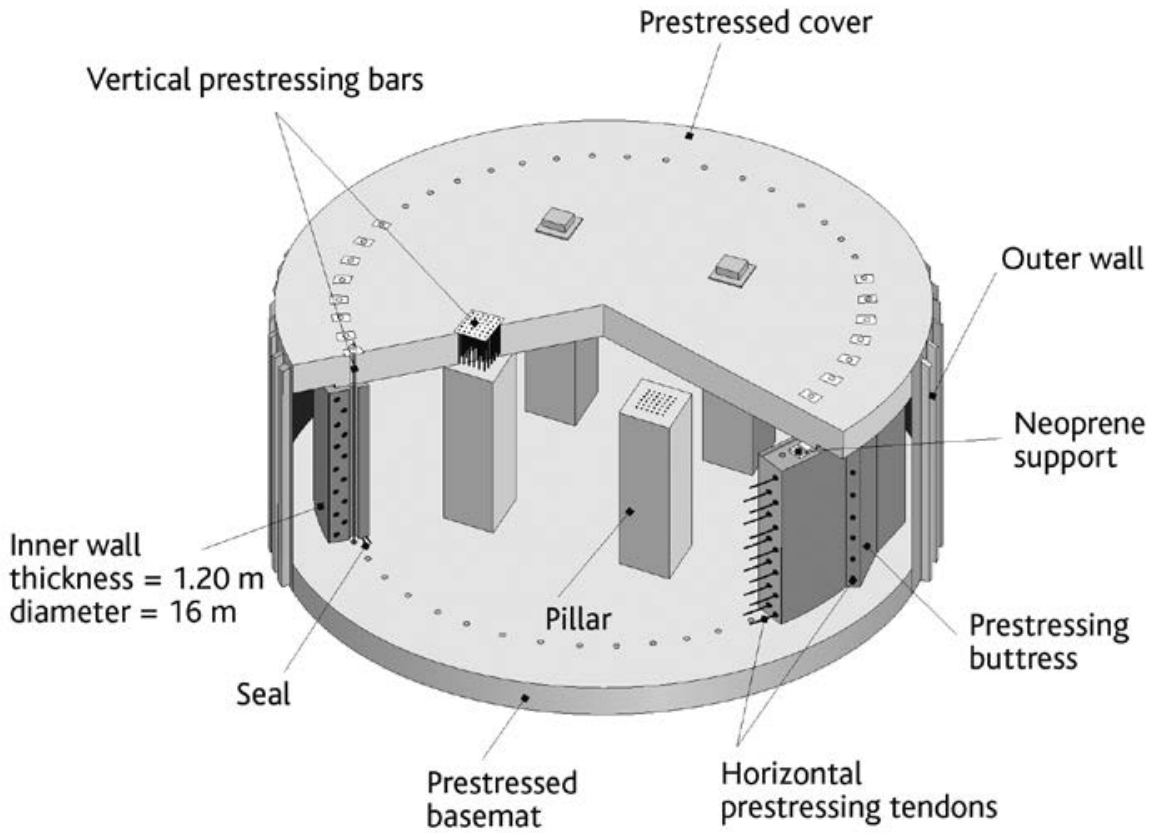

Figure 6.10. Schematic diagram of the MAEVA scale model. 
divided into quadrants, two of which were covered with a composite-material sealing layer similar to that used for repairs on units in operation.

As for units in operation, the prestress was calculated to obtain, at a pressure of 6.5 bar abs., a mean residual compression of $1 \mathrm{MPa}$.

Several tests were performed on this scale model, with air and with a mixture of air and steam, up to the design pressure of the scale model (5.5 bar rel.). To represent core melt accidents, a test with air was performed at a pressure of 9.75 bar rel. (see Figure 6.11).

During each test, the purpose of the measurements performed was to determine leakage rates into the annulus, divided into four sealed quadrants (each quadrant was called a chamber), with dry air and with a mixture of air and steam, along with temperatures in the containment and the concrete wall, pressure in the containment and displacements of the inner wall of the scale model. In addition, a survey of cracks, visual monitoring of the composite-material coatings and bond tests for these coatings were performed. These last tests quantified the adhesion of the coatings on the concrete wall after the test sequences.

Analysis of the results also determined the adjustment coefficient to be used between the leakage rate for dry air and the leakage rate for a mixture of air and steam. This coefficient was then used to determine the leakage rate of real containments under accident conditions based on leakage rates measured during tests. In addition, changes in cracking and measured leakage rates were determined for several accident scenarios. In particular, these results on changes in cracking and measured leakage rates have been used to validate the method for quantifying leaks described in Section 6.3.3.1 (the CEOS project launched by EDF and the ECOBA project funded by ANR, which have just been completed at the time of writing).
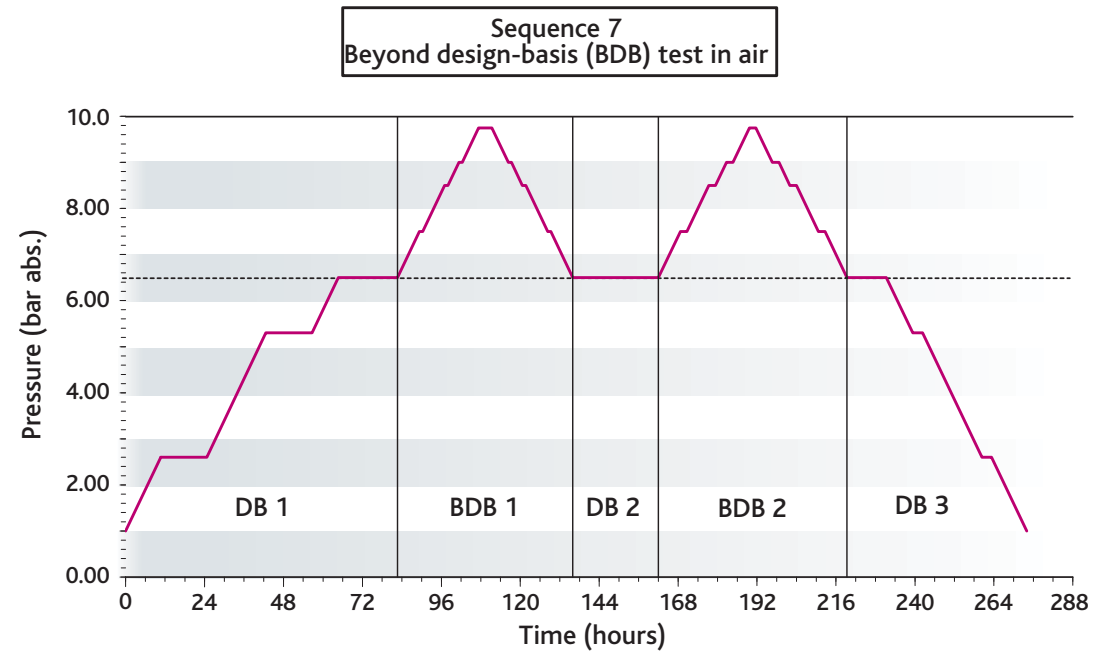

Figure 6.11. Pressure changes during the test performed on the MAEVA model, for core melt accidents. 


\subsubsection{Summary and outlook concerning studies performed by IRSN regarding the mechanical behaviour of containment buildings under core melt accident conditions}

\subsubsection{Summary and outlook for the containments of 900 MWe PWR power plants}

The nonlinear simulations performed by IRSN determined the mechanical behaviour of the containment buildings of 900 MWe power plants under core melt accident conditions, and specifically, the behaviour of the sensitive areas of these structures. Leak tightness of these containments is provided by a metal layer on the internal face of the containment. Taking experience feedback into account, the test results were used to specify a criterion for loss of leak tightness of the metal layer, suitable for finite element simulations.

The value adopted for the pressure leading to loss of leak tightness of such a containment is about 10 bar abs. (twice the design pressure). However, it should be noted that the simulations were performed for an ideal liner, without taking into account any defects that might exist in the welds or any degradation by corrosion, as these phenomena are very difficult to simulate on a computer. For this reason, a safety coefficient should be assigned to the pressure given above, depending on the extent of knowledge of the aforementioned phenomena, in order to determine the failure pressure for such a containment.

The results could be extrapolated to core melt accident scenarios other than the AF scenario. This extrapolation is possible because the mechanical phenomena depend mainly on the pressure.

With regard to the leak tightness of the equipment hatch, the local and detailed models brought to light two modes of loss of confinement, corresponding to tensile failure and shear failure of the bolts. These two failure modes show threshold effects that depend on the choice of bolts and the specific conditions of each facility (initial free play between bolt shank and flange bore, the surface state of the flanges, friction etc.). In all cases, regardless of the failure mode, these studies confirmed the vulnerability of the flange closure system adopted at design, under core melt accident conditions. In order for the containment to resist an accident pressure of at least 8 bar abs., EDF has decided to change the bolts (changing both grade and diameter) on the equipment hatch.

Other than the equipment hatch, the behaviour of the other sensitive areas of the containment, such as the various penetrations, must also be considered for core melt accident conditions, as the containment failure pressure also depends on this behaviour. EDF is working on this subject as part of safety reviews to check the behaviour of equipment under severe accident conditions. 


\subsubsection{Summary and outlook for the containments of 1300 MWe PWR power plants}

In the context of performing a level 2 PSA for 1300 MWe PWR power plants, IRSN produced an approach to the study of the behaviour of double-wall containments. This will be used from 2014 during discussions concerning the safety review associated with the third ten-yearly outage programme for 1300 MWe PWR power plants.

However, this approach, which is based on the results of containment pressure tests and tests performed using the MAEVA scale model, is subject to significant uncertainties as concrete cracking is difficult to characterise and the quantification of leakage via cracks is therefore imprecise.

Improvement of knowledge in these two areas is the subject of two projects whose results and their analysis are expected in 2015:

- the 4-year CEOS project, led by the institute for applied research and experimentation in civil engineering (IREX). IRSN was a participant in this project, whose objectives were to study the cracking of concrete walls or shells under various loads (static monotonic loading, early behaviour in the ten days after pouring, effect of constrained deformations, and cracks due to an earthquake);

- the ECOBA project, funded by the French National Research Agency (under the ANR Blanc programme) for a period of three years. The objective of this project was to develop a reliable tool for assessing leakage thorough a reinforced or prestressed concrete wall under severe pressure load conditions possibly combined with a thermal load.

These two projects had complementary objectives, and include a computer modelling and an experimental aspect. Studies using the developped modelling are expected this year.

\subsection{Containment bypass}

\subsubsection{Introduction}

The term "containment bypass" covers situations which, following equipment failure, lead to reactor coolant being put into direct contact with the outside of the containment building (i.e. into peripheral buildings or directly into the environment).

Containment bypass could occur during normal reactor operation, during a designbasis accident (in particular, a steam generator tube rupture accident), or during a core melt accident.

Core melt accidents with containment bypass are among the situations that should be "practically eliminated" because they could lead to large early release of radioactive materials. Generally, these situations have not been covered in design for the reactors in the current French fleet, because they result from multiple failures or have a very low probability of occurring. 
In contrast, these containment bypass situations have been covered in EPR design via suitable design and operating provisions. The purpose of these provisions is to prevent failures on the secondary systems in the event of steam generator tube rupture (SGTR), and failures on systems connected to RCS that leave the containment building. They also aim to ensure reliable confinement in these situations (such that the objectives set for the EPR in terms of limiting releases are met in all cases). The following provisions are among those that contribute to practical elimination of accident sequences with containment bypass for the EPR:

- design provisions on the low head safety injection system (LHSI/RHR, connected to the RCS in particular in certain LOCA situations or during reactor shutdown), whose injection lines outside the containment building are fitted with motor-driven isolation valves that can prevent flow of any fluid from the RCS (in the event of failure of the isolation devices - three non-return check valves - located upstream inside the containment building). The valves are therefore designed to maintain their integrity and provide their isolation function for RCS temperatures and pressures and for two-phase water-steam mixtures;

- design provisions on the medium head safety injection system (MHSI, connected to the RCS in particular in certain LOCA situations) similar to those implemented for the LHSI/RHR;

- design provisions made to detect and isolate breaks in the thermal barriers of the reactor coolant pumps (RCP);

- design and operating provisions implemented for SGTR situations with a view to reducing releases outside the containment building:

- the MHSI has been designed with a sufficiently low discharge pressure as to avoid loading the relief and blowdown valves of the relevant steam generator secondary system with a two-phase water-steam flow that could damage them;

- in the event of high water level on the secondary side, the chemical and volume control system (CVCS) is automatically shut down for the same reasons;

- for reactor shutdown states, design and operating provisions for containment isolation systems which must be implemented to ensure that the containment building will be closed before any significant release of radioactive substances into it; this requirement affects the equipment hatch in particular.

Practical elimination of containment bypass situations during a core melt accident is based on systematic consideration of all conceivable bypass sequences, with a deterministic analysis of the corresponding lines of defence, supplemented by probabilistic safety analyses, taking into account uncertainties due to limited knowledge of certain physical phenomena. As specified in the technical directives for the design and construction of the next generation of PWR power plants, practical elimination of an accident sequence cannot be based uniquely on compliance with a generic probabilistic cut-off point. This applies to containment bypass sequences, especially as probabilistic assessments of such sequences, which are associated with large early releases into the 
environment, generally depend mainly on estimating the frequency of failure modes for equipment that may contribute to confinement. These failure modes include those already encountered on operating reactors (non-return check valve leakage, isolation valve failure, pipe break on a system connected to the RCS outside the containment building, failure of an RCP thermal barrier, SGTR etc.), and others that have not been encountered in operating experience. For this reason, uncertainties regarding the reliability data for various systems and equipment items whose failure could lead to containment bypass must be assessed and taken into account during use of the results of probabilistic safety analyses.

\subsubsection{Possibilities for containment bypass}

During normal reactor operation, failure of isolation between the RCS and one of the systems connected to it (in particular, the SIS, RHR, CVCS and CCWS for reactors in the current French fleet) could lead to a line break outside the containment building on the system involved. These systems are not designed to withstand loads resulting from the arrival of reactor coolant (a water-steam mixture at high temperature and pressure) following isolation failure (i.e. failure of a check valve or isolation valve for the SIS, RHR and CVCS, failure of an RCP thermal barrier for the CCWS). Along with the possibility of a pipe break outside the containment building, the heat exchangers used for cooling the RHR, CVCS and CCWS are mechanical weak points. Leakage possibilities are therefore considered.

During design-basis accidents such as SGTR or LOCA, containment bypass may occur in the following cases:

- the combination of a main steam line break (MSLB) and an SGTR;

- a valve on the main steam relief train (MSRT) or a steam generator relief valve jamming in the open position following an SGTR;

- rupture on a system in a peripheral building that constitutes an "extension of the third containment barrier" (see Section 6.1), including the safety injection system (SIS) and the containment spray system (CSS), following LOCA.

Finally, the following types of containment bypass could occur during a core melt accident:

- a single or multiple SGTR caused by an increase in pressure in the RCS when water drains back onto the molten core;

- a line break on the SIS due to a leak affecting the isolation valves fitted to the safety injection lines;

- a line break on a system that is part of the extensions to the third containment barrier (line break on a system connected to the RCS or failure of an RCP thermal barrier).

The following sections give examples of several types of containment bypass. 


\subsubsection{Types of containment bypass that could occur during reactor operation}

\subsubsection{Rupture on the safety injection system (SIS) following a leak affecting the isolation valves fitted to the safety injection lines in the RCS}

In the event of a sealing fault on the isolation devices (check valves) located between the "low head" part of the SIS and the RCS, rupture could occur on the low head part of the SIS (LHSI), due to pressurisation of this part if the leak exceeds the capacity of the SIS safety valves. Such rupture would lead to water from the RCS draining outside the containment building. Depending on valve failure mode, the calculated flowrate from the RCS would be between $25 \mathrm{~m}^{3} / \mathrm{h}$ and $1000 \mathrm{~m}^{3} / \mathrm{h}$.

Estimated frequencies for these "type V" accident sequences, depend on the number of isolation devices and the probabilities of failure, including common cause failure, assigned to these devices. As these probabilities of common cause failure for the various check valves providing RCS isolation are low, the probability of a core melt accident with containment bypass is estimated at approximately $10^{-8}$ per reactor-year for $900 \mathrm{MWe}$ reactors, given that there are three check valves, two of which are diversified. However, this value is subject to large uncertainties.

\subsubsection{Break on the component cooling water system (CCWS) outside the containment building following failure of a reactor coolant pump thermal barrier}

The RCP thermal barriers are cooled by coils which are part of the CCWS. Failure of such a coil could lead to rupture on sections of the CCWS not designed for RCS pressure. This would lead to an RCS break that cannot be isolated. As described below, the break could occur inside or outside the containment building, leading to containment bypass in the latter case.

For 900 MWe units, each RCP is cooled by a part of the CCWS that penetrates the containment building. Inside the containment, isolation of each cooling line (one line per RCP) is reliant on the closure of a non-return check valve located on the CCWS upstream of the RCP and on closure of a pneumatic valve located on the CCWS downstream of the RCP. Valve closure is automatic in the event of excessive flowrate in the CCWS at the outlet of the RCP thermal barrier (excessive flowrate may occur following coil rupture leading to reactor coolant leaking into the CCWS). The section between the non-return check valve and the isolation valve is able to mechanically withstand the temperatures and pressures associated with leakage of reactor coolant into the CCWS, as shown by mechanical calculations performed by IRSN to this end. However, in the event of failure of the non-return check valve or the isolation valve, which are not designed to ensure isolation of the CCWS during a reactor coolant leak (in particular for the corresponding temperatures and pressures and two-phase watersteam mixtures), a break in the CCWS could occur inside or outside the containment 
building on sections of the system other than the section between the non-return check valve and the isolation valve.

The estimated frequency of a core melt accident with containment bypass during such a break in the CCWS depends on the ability of the CCWS isolation valve to close. Given the large uncertainties concerning this ability and as part of the safety review associated with the third ten-yearly outage programme for 900 MWe units, ASN requested implementation of a design modification to ensure the availability of the CCWS in the event of thermal barrier coil rupture.

For $1450 \mathrm{MWe}$ reactors, following their first ten-yearly outage programmes, ASN requested that the operator present a detailed analysis of accident scenarios of this type in 2014.

For $1300 \mathrm{MWe}$ reactors, the subject is under examination as part of the safety review associated with the third ten-yearly outage programmes.

For the EPR, the estimated frequency of core melt is very low given that CCWS isolation is qualified to be operable in the event of a guillotine break in the coil and is provided by two diversified valves. Furthermore, by design, only partial loss of CCWS would occur in the event of failure of this isolation.

\subsubsection{Types of containment bypass that could occur during a design-basis accident}

This section describes containment bypass associated with steam generator tube rupture (SGTR).

SGTR leads to reactor trip and automatic startup of the safety injection system (SIS) and the emergency feedwater system (EFWS). The main actions to be performed by the operator are as follows:

- identify the affected steam generator and isolate it on the secondary side. This isolation must be performed quickly to avoid the steam generator filling with water and consequent loading of the associated blowdown and relief valves;

- cool the reactor via the healthy steam generators and reduce RCS pressure to stop the primary-secondary leak as quickly as possible and create the conditions for startup of the RHR system. Using specific criteria, operators must shut down the SIS to limit filling of the steam generator with water and allow depressurisation of the RCS.

The path to cold shutdown is pursued by starting up the RHR system.

Following an SGTR, containment bypass may result from a leak of reactor coolant via the secondary system blowdown or relief valves occurring after filling of the secondary side of the affected steam generator by reactor coolant. Such a situation could occur if there were a delay in the operator isolating the affected steam generator or shutting down the safety injection system and if the secondary system blowdown or relief valves 
should fail to close after operating with water, followed by failure of the RHR system during its startup or operation, which would lead to complete drainage of the refuelling water storage tank (RWST) to the outside of the containment building, thereby making it impossible to provide water injection into the RCS.

In order to reduce the risk of a combination of an SGTR and failure of a secondaryside relief-valve, modifications have been made to reactors in the current French fleet to limit filling of the secondary side of the affected steam generator with water from the RCS, in order to prevent steam generator overflow. Note that the situation is more favourable on $1300 \mathrm{MWe}$ and $1450 \mathrm{MWe}$ units and the EPR, as the SIS discharge pressure (MHSI on the EPR, see Section 6.4.1) is lower than on 900 MWe units. Results of the PSAs show that the probability of a core melt accident with containment bypass associated with an SGTR is very low (less than $10^{-8}$ per reactor-year for 900 MWe reactors).

\subsubsection{Types of containment bypass that could occur during a core melt accident}

\subsubsection{Induced breaks on steam generator tubes}

One of the main risks associated with high-pressure core melt accidents is containment bypass following steam generator tube rupture (SGTR).

Existing studies concerning high-pressure core melt accidents, in particular those performed at IRSN, show that RCS failure would initially occur on steam generator tubes (i.e. before hot leg or reactor vessel failure) when these are depressurised (see Section 5.1.4). Furthermore, operating experience feedback has shown that certain steam generator tubes are weakened by reactor operation (weakening by corrosion and fatigue mechanisms). Despite provisions made to monitor the state of the tubes and isolate weakened or corroded tubes (see Section 2.4.2.3), the existence of weakened tubes which constitute one of the mechanical weak points of the RCS pressure boundary cannot be ruled out.

Provisions have been made that aim to prevent high-pressure core melt accidents, given the possible consequences of this type of accident on the third and final containment barrier, in particular in the event of direct containment heating (DCH, see Section 5.2.1). These provisions include deliberate depressurisation of the RCS by opening the pressuriser steam bleed valves. This depressurisation of the RCS is included in the accident operation procedures and is performed immediately by the operators as soon as the Severe Accident Operating Guide is in use (see Section 4.3.3.4).

It should be noted that, in the context of the safety review associated with the third ten-yearly outage programme for 900 MWe reactors, it has been decided to modify the opening control for pressuriser steam bleed valves to make their operation more reliable and thereby make it possible to depressurise the RCS during a core melt accident.

For the EPR, design provisions have been made aiming to "practically eliminate" highpressure core melt accidents. These are described in Section 4.3.4.2. 
Please refer to Section 5.1.4 for more details regarding high-pressure core melt accidents and "induced breaks".

\subsubsection{Failure of a system that constitutes an extension of the third containment barrier}

Systems called "extensions of the third containment barrier" (E3B) are systems required for the management of a given accident situation, whose startup requires the opening of containment isolation valves. A failure (such as a leak or line break) on these systems may lead to transfer of radioactive substances into the buildings around the reactor building or into the environment.

For $900 \mathrm{MWe}$ units, systems that constitute an extension of the third containment barrier during a core melt accident include, in particular:

- the section of the containment building venting and filtration system between the containment isolation valve and the outlet of the sand filter. This system and its uses are described in Section 4.3.3.3;

- the sections of the SIS and CSS systems outside the containment, which carry contaminated water from the sumps located at the bottom of the reactor building when these systems are used in recirculation mode (see Section 2.4.2).

The decision to start up an E3B system can be made by applying the Severe Accident Operating Guide. The decision could also have been made earlier in the course of an accident, in application of the Assistance Guide for Emergency Response Teams.

The definition of an extension of the third containment barrier, the list of E3B systems and the requirements to be applied to these systems are subject to detailed examination by IRSN and EDF, in particular during safety reviews.

In this respect, it should be specified that the concept of an E3B system appeared after the design phase for the facilities. For this reason, the process of applying the requirements associated with the third containment barrier to its extensions has been performed in a checking framework rather than a design framework for reactors in the current French fleet. Initially, this process aimed to check the ability of E3B systems, as designed, to:

- mechanically withstand the loads induced by their role which involves checking via mechanical studies performed on all series;

- ensure confinement of radioactive substances under all conditions to which they might be subject, in particular under accident conditions that require their use.

This IRSN examination of the requirements that apply to E3B systems as part of the safety reviews associated with the third ten-yearly outage programmes for $900 \mathrm{MWe}$ reactors and the second such programmes for $1300 \mathrm{MWe}$ reactors has led to requests to check the mechanical resistance of certain systems which could carry a water-steam mixture under accident conditions (in particular for the NSS/RCS) and the irradiation 
resistance of certain equipment items (in particular the seals required for leak tightness of E3B systems).

This examination also led to implementation of modifications to equipment and procedures, with the aim of both ensuring better detection of possible failures on E3B systems and of mitigating consequences in the event of failure of these systems.

With regard to monitoring the leak tightness of E3B systems (in particular the SIS and CSS), additional activity measurements (on the plant radiation monitoring system) and measurements of the water level in the sumps of the nuclear auxiliary building, fuel building and auxiliary safeguard building have been implemented on the facilities.

With regard to means for mitigating any consequences in the event of failure on the systems, EDF's current strategy consists of reinjecting the contaminated effluents recovered outside the containment back into the containment, whether for design-basis accidents or core melt accidents. Analysis of the modifications associated with this strategy, which have already been implemented for the $900 \mathrm{MWe}$ series as part of the third ten-yearly outage programmes, is currently underway at IRSN for the $1300 \mathrm{MWe}$ series as part of the safety review associated with the third ten-yearly outage programmes for these reactors.

\subsection{Conclusion}

As shown by the Three Mile Island accident in the United States (see Section 7.1), the containment building provides effective confinement during a core melt accident when its integrity and leak tightness can be ensured. Studying possible failure modes of the containment building and assessing means to confront them contributes to reducing the possibility of radioactive releases into the environment for all conceivable accident situations, including core melt accidents.

As we have seen in this section, studies regarding containment consist of systematic examination of possible failure modes under all conceivable operating conditions: leak tightness failure on the reactor building itself, leak tightness failure on containment penetrations, failure on systems connected to the RCS which under certain operating conditions constitute "extensions of the containment building".

In particular, the purpose of these studies is to improve the design and operating provisions implemented on containments in the current French fleet, to prevent the risk of large releases into the environment in the event of a core melt accident as far as possible. For reactors in the current fleet, studies have also enabled improvements to equipment hatch leak tightness by modifying the associated fastenings.

For the design of the EPR, a stricter objective was adopted: to "practically eliminate" core melt accidents that could lead to large early releases. 


\section{Reference Documents}

[1] B. Masson, Tenue du confinement, évaluation des transferts à travers la paroi de l'enceinte, réunion sur la recherche et développement concernant les accidents graves, SFEN, Cadarache, France, 2009 (in French).

[2] E. Raimond, B. Laurent, R. Meignen, G. Nahas, B. Cirée, Advanced Modelling and Response Surface Method for Physical Models of Level 2 PSA Event Tree. CSNIWG-RISK-Workshop level 2PSA and Severe Accident Management, Cologne, Germany, 2004.

[3] B. Cirée, G. Nahas, Mechanical analysis of the equipment hatch behaviour for the French PWR 900 MWe under severe accident, H01/3 - Proc. SMiRT, Toronto, CANADA, 2007.

[4] G. Nahas, B. Cirée, Mechanical analysis of the containment building behaviour for the French PWR 900 MWe under severe accident, H05/5 - Proc. SMiRT, Toronto, CANADA, 2007.

[5] M. F. Hessheimer, R. A. Dameron, Containment Integrity Research at Sandia National Laboratories, NUREG/CR-6906 SAND2006-2274P, 2006.

[6] OECD International Standard Problem No. 48, Containment capacity, Phase 2 Report Results of Pressure Loading Analysis, Organization for Economic Cooperation and Development, Nuclear Energy Agency, Committee on the Safety of Nuclear Installations, NEA/CSNI/R(2004)11, 2004.

[7] OECD International Standard Problem No. 48, Containment capacity, Synthesis Report, Organization for Economic Cooperation and Development, Nuclear Energy Agency, Committee on the Safety of Nuclear Installations, NEA/CSNI/R(2005)5/ Vol. 1, 2 and 3, 2005. 
